\title{
A Novel Architecture to Plan and Execute Industrial Visit for Educational Institutes
}

\author{
Mohil Tanti \\ Under Graduate Student, Faculty \\ of Engineering \\ Marwadi Education Foundations \\ Group of Institutions, Rajkot, \\ Gujarat, India
}

\author{
Foram Aghara \\ Under Graduate Student, Faculty \\ of Engineering \\ Marwadi Education Foundations \\ Group of Institutions, Rajkot, \\ Gujarat, India
}

\author{
Ashish Revar \\ Sr. Asst. Professor, CE Dept. \\ Marwadi Education Foundations \\ Group of Institutions, Rajkot, \\ Gujarat, India
}

\begin{abstract}
Industrial visits possess a vital role in the current education system as the students should have theoretical as well as practical knowledge for their better future. When students get a perfect exposure to the working environment they get mentally prepared and also career oriented as to in which field they should continue in future. A perfect well organized industrial visit can help students to enhance their vision and also help them to set long-term goals of their life. An automated system can be made for organizing visits, by which all the activities related to organizing could be brought online and make the management much easier and follow a genuine structure. The focus of this paper is on analyzing the travel planners and other products used by the market/people.
\end{abstract}

\section{General Terms}

Company, Visit, Planner, Colleges/Universities

\section{Keywords}

Student, Industry, Visit, Colleges, Portal and Planner.

\section{INTRODUCTION}

\subsection{Planner}

A structured and streamlined planner is required to make the planning of visits more transparent and ease the execution of work. Currently, the way information conveyed to students is not much reliable and there is a possibility of miscommunication, so an online portal with structured workflow may overcome this issue and as well as parents can also be updated by the activities performed which would eliminate the issue of false information passing by students.

\section{Admin}

Role of admin will be to manage all the other users and also keep track of all activities.

\section{Faculty}

Faculty will manage trips over portal for the participants of the visit. Faculty will manage communications among students, parents, agent and company resource persons.

\section{Students}

Role of the students will be to register themselves for visit, and also perform activities directed by faculty on the portal.

\section{Parents}

Parents will be able to track all the activities done by the student as well as faculty, and also can provide feedback later on.

\section{Company Resource Persons}

Company Resource Persons will be responsible for approving the requests for visits, for providing rules and regulations of the firm and also listing the activities to be performed while visit.

\section{Agent}

Role of the agent will be to issue travel insurance of all the students as well as faculties attending the visit and providing the regular status of activities while visit is going on which will be visible to parents and students.

\subsection{Industrial Visit}

Industrial visit is a part of professional courses, during which students visit the companies and get insights into the internal working environment of the company. Industrial visits sensitize students to the practical challenges that organizations face in the business world. Sometimes students also get opportunities to get hands-on experience of the current tools and technology on which company is working.

\subsubsection{Types of Visit}

Instate visits

Instate visits are generally visits conducted within the state in nearby cities and generally small companies or research institutes. Instate visits are of 1-2 days.

\section{Outstate visits}

Outstate visits are conducted out of state in big/metro cities and generally big companies or research institutes. Outstate visits are generally of 6-7 days.

\section{LITERATURE REVIEW}

\subsection{Method and Tour Planner for Planning Tour for a Group}

Muthuramalingam, et al. [1] invented a method, a tour planner, and a computer program product for planning a tour for a group including one or more travelers. In various embodiments of the invention, the tour planner enables a traveler to select a travel route and simultaneously share the selected travel route with at least one other traveler. Thereafter, based on the feedback of the other traveler, the selected travel route is either changed or finalized by the group. Further, the method facilitates the group of travelers on the day of the travel by providing each one of them with one or more alerts relating to the finalized travel route.

\subsection{Direct user to Ticketing Service \\ Provider Secure Transaction Channel}

Pitroda, et al. [2] developed a system in which ensuring security of electronic transactions between a user and a ticketing service provider involves establishing trust between a user and a transaction service provider, authenticating an electronic transaction facility of the user, establishing a secure communication channel between the user and the ticketing 
service provider, and registering the user with the ticketing service provider over the secure communications channel.

\subsection{Mobile Payments Integrated with a Booking System}

Angrish, et al. [3] introduced a booking system in which the service provider computer system is communicatively coupled to a computing device of a user and a merchant point-of-sale computer by one or more data networks. The method comprises: receiving a request from the computing device of the user to pay a ticket open at the merchant point-of-sale computer; obtaining a current total ticket amount for the ticket from the merchant point-of-sale computer; determining an estimated total ticket amount based at least in part on the current total ticket amount; authorizing but not capturing payment of the estimated total ticket amount with a payment network gateway computer; after the ticket is closed at the merchant point-of-sale computer, obtaining a final total ticket amount for the ticket from the merchant point-of-sale computer; and capturing payment of the final total ticket amount with the payment network gateway computer.

\subsection{Methods and Systems for Online Access Credential Transition}

Kanevsky, et al.[4] suggested systems and methods for online access credential transition, including receiving a first string of elements associated with a subsequent online access credential, during a credential transition period, receiving a second string of elements associated with an attempted subsequent online access credential, performing a matching operation to determine a degree of matching between the first string of elements and the second string of elements, and based on the degree of matching between the first string of elements and the second string of elements, providing online feedback, and prompting another attempted subsequent online access credential.

\subsection{System and Method for Managing Data and Updates to a Database Structure}

Gardner, et al. [5] developed a system that manages database structure updates. The system may receive, via a development gateway, a development script. The system may also copy, via a backup engine to an update module, an existing object code. The system may deploy, via an update engine, the development script directly to the database structure. The system may also generate a new object code within the database structure associated with the existing object code. The system may determine, via a database health monitoring module, at least one of a successful deployment of the new object code or an unsuccessful deployment of the new object code.

\subsection{Method and a System for Providing An Interactive location service}

Lim, et al. [6] invented method and a system for providing interactive location service to a user. The system enhances the location service experience to the user by integrating other technologies to create an intelligent platform and GPS location mapping with high-resolution spherical images. Further, the proposed method and system offers centralization of data and relatively more efficient and less error-prone.

\subsection{Method and System for Managing ITINERARY}

Jang, et al. [7] developed method and a system for easy management of an itinerary. The method includes generating, by an electronic device, a trip route, selecting a trip item for recommendation information searching, searching for recommendation information of the selected trip item based on the generated trip route, displaying the searched recommendation information at a corresponding location on the generated trip route, modifying the generated trip route based on selected recommendation information from the displayed recommendation information, and storing the modified trip route.

\subsection{Automated Internet based Interactive Travel Planning and Management System}

Block, et al. [8] invented a system which includes a webbased planning and reservation interface system and an interactive access device. The system responds to details of a member's desired travel, to thereafter act in real time to contact the domains of associated travel service providers to arrange for every aspect of the member's trip, from airline and hotel reservations, ticket issuance, and ground transportation, to restaurant and theater reservations, and any other travel related needs of the member. The system stores identification information to verify access device possession to prohibit unauthorized use of the system and to provide security preclearance to system members.

\subsection{Method and System for Targeting Messages to Travelers}

Depasquale, et al. [9] proposed method and system in which requests can be received to transmit messages to a traveler based on a location and a categorization of the traveler. A device location can be received. Location information of the traveler can be determined. Prior expense report information can be determined. Entity expense policy can be determined. The location information, the prior expense information, and the entity expense policy information can be categorized to generate a projected route. Updated device location can be received. It can be determined that the device is in a location corresponding to the projected location information based on the updated device location. Any targeted messages that have a category that matches a category for the location information, the prior expense information and the policy information can be transmitted to a device of the traveler.

\subsection{Weather Information Delivery Systems and Methods Providing Planning Functionality and Navigational Tools}

Ryan, et al. [10] developed a weather system, available through the Internet provides for clean and consistent global navigation, brings content close to the consumer, and allows consumers to plan their lives based on the weather. On a local weather page, the information is organized in a hub-and-spoke fashion so that consumers can navigate to interrelated information. The weather system can quickly give consumers the local weather at any location, but also empowers consumers to plan their lives based on the weather. The weather system provides consumers with multiple methods of navigating through the site, including geographical, categorical/activity-based, localized/contextual, and temporal.

\subsection{Route-based Activity Planner}

Seltzer, et al. [11] invented a system in which the objectives can be arranged automatically and an associated route can be produced such that the objectives can be completed in an effective manner. Data related to the objectives can be 
collected such as a traffic pattern on paths near a location the objective is to take place. Locations for the objectives to be completed can be determined automatically as well as provided by the user. Analysis of the collected data can take place and based on a result of the analysis, an efficient route is produced.

\subsection{System and Method for Managing Seat Reservations}

Halavais, et al. [12] developed a system and method by which people can select the exact seat or seats they want for any type of event or reserve an appointment for any activity. More specifically, a customer or a ticket re-seller or a venue operator can go, for example, to the internet and select the event or activity for which he wants a ticket or tickets or reserves time and reserve and order the exact seat or seats or the time of his choosing directly online. The seat or seats or the reserved time he selects is then removed from the inventory for that activity or event and made not available for any other buyer and such is so indicated by a graphical representation or another such indicator on the online map or picture representing the availability of seating or time for that event.

\subsection{Secure Transaction Interfaces}

Peled, et al. [13] introduced systems and methods for secure transaction interfaces. In one implementation, a processing device receives, within a user input interface and while a user communication agent is presented at a display interface of a device, a selection of a transaction initiation control, presents, in response to the selection of the transaction initiation control and via the user input interface, a transaction execution control, presents, in response to a selection of the transaction execution control, identifier(s) via an identifier selection control, receives a selection of the identifier(s), transitions, in response to the selection of the identifier(s), the user input interface into a numeric input interface, receives a numeric input via the numeric input interface, activates a transaction confirmation control within the user input interface, and executes, in response to a selection of the transaction confirmation control, a secure transaction with respect to the selected identifier(s) and the numeric input.

\subsection{System for Providing Tourist \\ Tracking on a Mobile Device}

Dornfeld [14] developed a system for tourist tracking comprising at least one tourist, at least one vehicle, and at least one director each having a communications device and a GPS system in communication thereto. Tourists are provided with notifications alerting them to excursions created by the directors. The system is a cross-platform application accessible by PED operating systems. Three separate user interfaces are utilized including a vehicle-associated system, a director (tour guide) associated system, and a touristassociated system. A vehicle-associated user having a communications device with a GPS system is positioned on the vehicle. The director has a PED with a GPS in communication with the PED. Further, at least one tourist has a communications device having a third GPS in communication thereto. A network connects each user along with a database and server. Processors at each device operate in a plurality of processes specific to each user.

\subsection{Appointment and Payment Handling}

Myrick, et al. [15] developed an appointment and payment handling system may operate to handle payments for appointments. In advance of an appointment, the appointment and payment handling system may send a reminder to customer devices of the customers associated with the appointment, and then receive a response that includes a requested change to the appointment. The requested change may comprise a net increase in the number of customers associated with the appointment and an updated cost-splitting arrangement for dividing appointment costs between the customers. The appointment and payment handling system may seek and receive approval of the change from the merchant. Upon determining that the appointment is completed, the appointment and payment handling system may process a payment based at least in part on the updated cost-splitting arrangement.

\section{COMPARATIVE STUDY OF EXISTING SYSTEM}

Attracting new colleges/universities and then retaining them is critical for the success of this type of planning website. Providing trustworthy service and flexibility to the users is quite crucial to exceed their expectations and satisfy them, which would attract the new users as well as hold existing ones.

The educational system is advancing nowadays where classrooms are getting digitized but one area where it is lacking behind is in organizing industrial visits in a systematic manner. Institutes are generally looking for an alternative easy way of all the manual works. So what lies ahead is an online portal providing all automation of manual works and providing insights into activities.

Table 3.1 Comparison with the existing system

\begin{tabular}{|c|c|c|c|c|c|c|}
\hline & $\begin{array}{c}\text { TripIt } \\
{[16]}\end{array}$ & $\begin{array}{c}\text { Tourist- } \\
\text { Eye } \\
{[17]}\end{array}$ & $\begin{array}{c}\text { TripCase } \\
{[18]}\end{array}$ & $\begin{array}{c}\text { Trip- } \\
\text { Advisor } \\
{[19]}\end{array}$ & $\begin{array}{c}\text { World- } \\
\text { Mate } \\
\text { [20] }\end{array}$ & $\begin{array}{c}\text { Proposed } \\
\text { Architect } \\
\text { ure-IV } \\
\text { Planner }\end{array}$ \\
\hline $\begin{array}{c}\text { Undertaking } \\
\text { generation }\end{array}$ & $\mathbf{x}$ & $\mathbf{x}$ & $\mathbf{x}$ & $\mathbf{x}$ & $\mathbf{x}$ & $\checkmark$ \\
\hline $\begin{array}{c}\text { Industry } \\
\text { feedback }\end{array}$ & $\mathbf{x}$ & $\mathbf{x}$ & $\mathbf{x}$ & $\mathbf{x}$ & $\mathbf{x}$ & $\checkmark$ \\
\hline Bonafide & $\mathbf{x}$ & $\mathbf{x}$ & $\mathbf{x}$ & $\mathbf{x}$ & $\mathbf{x}$ & $\checkmark$ \\
\hline Hotel reviews & $\checkmark$ & $\checkmark$ & $\checkmark$ & $\checkmark$ & $\checkmark$ & $\mathbf{x}$ \\
\hline $\begin{array}{c}\text { Trip Insights } \\
\text { Transportation } \\
\text { reservation }\end{array}$ & $\checkmark$ & $\mathbf{x}$ & $\checkmark$ & $\checkmark$ & $\checkmark$ & $\mathbf{x}$ \\
\hline
\end{tabular}

TripIt[16] allows users to plan their trip, manage all their trip data and organize it centrally. It is the world's highest-rated travel-organizing app, today released features that help travelers access information about the safety of the neighborhood they're visiting, as well as country-specific travel logistics for TripIt Pro users, within the TripIt app.

WorldMate[20] is a business-oriented system in which provide services like setting appointment destinations, connect to other people via LinkedIn integrated into the 
system, and many more. Lonely Planet erstwhile TouristEye[17] is not a planning app but helps you find the perfect destinations from the user's wishlist.

TripCase[18] gives travelers a single place to easily manage all the details of a trip. As changes occur to flight schedules, travelers can be notified directly on their smartphone or wearable device

TripAdvisor[19] is quintessential travel planning service, which helps the user to plan a trip from the beginning and is also the web's largest repository of hotel and destination reviews, ratings, photos, and other information. With over 500 million candid traveler reviews, it can help the user make the right choice when you shop for hotels, restaurants, and attractions. User's also can find low airfares, free travel guides, worldwide holiday rental listings, popular forums with advice about virtually every destination, and more. When it's time to book, it can help you save up to $30 \%$ on hotels, checking 200+ sites to find user today's lowest prices. And when the user's on the trip, our free mobile app is your ultimate travel companion.

One of the limitations of the above systems is that they don't plan industrial visits and its relevant activities. Undertaking forms are required for the parent's approval and college documentation and bonafide letters are required for providing proof that students are from a particular college, so these documents are not issued by existing systems.

\section{PROPOSED ARCHITECTURE}

Our proposed architecture - IV Planner will provide full automation and ease of execution to all the student-related and company related interactions with the faculty who is organizing the industrial visit. So basically all interactions and information gathering is done in this portal and faculty will be able to manage all the payment and students registered for the visit. IV Planner has basically 6 users: admin, faculty, student, parent, company person, and agent.

Admin will manage all the data of students, parents, faculties, company resource persons, and agents. Admin will get insights into all the activities performed by all the users and will be able to manage and notify users if any false information found. Admin will also be able to check all feedbacks from users and provide solutions to any queries raised.

Faculty will generate visit and itinerary and announce to participants for registration. Later on, faculty will get insights into the total amount of money collected from the participants, room preferences of participants, feedback and queries from participants and parents, etc., Faculty will also take company approvals over the portal and will be able to generate bonafide letters, undertaking forms, and trip invoices.

Students will be able to register themselves over the portal for the announced visit by faculty, download the undertaking forms, trip invoices, transportation tickets, and travel insurances generated, provide their room preferences, provide feedback and reports, and also be able to cancel their registration.

Parents will be able to track all the activities of their child, download the undertaking forms, trip invoices, transportation tickets, and travel insurances generated, provide feedback about the visit, get live status of current activities provided by faculty and agent, and see room preferences of their child.
Company Resource Persons will be managing approvals and notifying faculty about it, updating the rules and regulations which will be visible to faculty, students, and parents, and will be listing all the activities to be performed during the visit.

The agent will be responsible for issuing travel insurance to all the participants and faculty going for the trip which will be visible to parents and participants over the portal and keep parents regularly updated by providing status.

IV Planner mainly focuses on transparency and automation of organizing activities. The online portal provides easy management and flexibility to users.

\section{CONCLUSION}

From related study about the industrial visits and trip planners, proposed architecture will perform all activities related to organizing visits will be managed at one place for user easiness. In it, the faculty who is organizing the visit could open the portal for the intended students where students who are willing to go in the visit could register themselves which could help in maintaining the list online much better. The portal should also provide the functionality of live tracking of the students which will be accessible to parents. The portal should also notify users for any important announcements via SMS. Thus, proposed architecture will be providing these different functionalities for a user-friendly \& reliable system and to make planning better.

\section{REFERENCES}

[1] Muthuramalingam Prathesh Santh, Meganathan Sathis Kumar, "METHOD AND TOUR PLANNER FOR PLANNING TOUR FOR A GROUP”, US 20120016585 A1, Jan 19, 2012.

[2] Pitroda Satyan G., Desai Mehul, "DIRECT USER TO TICKETING SERVICE PROVIDER SECURE TRANSACTION CHANNEL", US 20160119332 A1, Apr 28, 2016.

[3] Angrish Rohan, Deshpande Rishi, "MOBILE PAYMENTS INTEGRATED WITH A BOOKING SYSTEM", US 20150178712 A1, Feb.2,2010

[4] Kanevsky Dimitri, Yung Marcel, "METHODS AND SYSTEMS FOR ONLINE ACCESS CREDENTIAL TRANSITION", 15/214,754, July 20, 2016.

[5] Gardner; Raymond L., Somavarapu Srinivas, "SYSTEM AND METHOD FOR MANAGING DATA AND UPDATES TO A DATABASE STRUCTURE", US 20170199922 A1, Jul 13, 2017

[6] Lim Kok Wing Jr, Esfahani Mehdi Zarrabi, "METHOD AND A SYSTEM FOR PROVIDING AN INTERACTIVE LOCATION SERVICE", US 20170363748 A1, Dec 21, 2017.

[7] Jang Yungeun, Kim Hyunsoo, "METHOD AND SYSTEM FOR MANAGING ITINERARY", US 20150046088 A1, Feb 12, 2015.

[8] Block David, Volny Jaro, et al., "AUTOMATED INTERNET BASED INTERACTIVE TRAVEL PLANNING AND MANAGEMENT SYSTEM", US 20110022425 A1, Jan 27, 2011

[9] Depasquale Thomas, Love John, et al., "METHOD AND SYSTEM FOR TARGETING MESSAGES TO TRAVELERS, US 20120101858 A1, Apr 26, 2012.

[10] Ryan Mark, Fennell Jody, Pearson Joe,“ WEATHER 
INFORMATION DELIVERY SYSTEMS AND METHODS PROVIDING PLANNING FUNCTIONALITY AND NAVIGATIONAL TOOLS", US 20070073841 A1, Mar 29, 2007.

[11] Seltzer Michael Lewis, Black Neil W., et al., "ROUTEBASED ACTIVITY PLANNER", US 20090210143 A1, Aug 20, 2009.

[12] Halavais Richard A., Chung Tony Cheng-Tong, "SYSTEM AND METHOD FOR MANAGING SEAT RESERVATIONS”, US 20130013354 A1, Jan 10, 2013.

[13] Peled Daniel, Markovich; Offer, "SECURE TRANSACTION INTERFACES", US 20180246623 A1, Aug 30, 2018.

[14] Dornfeld Gary, "SYSTEM FOR PROVIDING TOURIST TRACKING ON A MOBILE DEVICE",
15/860,050, January 2, 2018.

[15] Myrick Lauren, Ginsburg Evan, Ave Willem, "APPOINTMENT AND PAYMENT HANDLING", 14/498,755, September 26, 2014.

[16] TripIt | Travel Itinerary - Trip Planner - www.tripit.com as on $29^{\text {th }}$ Dec 2108

[17] TouristEye | Travel Guide - www.touristeye.com as on $29^{\text {th }}$ Dec 2108

[18] TripCase | Travel Organizer - www.tripcase.com as on $29^{\text {th }}$ Dec 2108

[19] TripAdvisor | Read Reviews, Compare Prices, and Book - www.tripadvisor.com as on $29^{\text {th }}$ Dec 2108.

[20] WorldMate | Travel Smart - www.worldmate.com as on $29^{\text {th }}$ Dec 2108 